\title{
Influência das variáveis contextuais no desempenho das equipes nos últimos 10 minutos do jogo de handebol
}

CDD. 20.ed. 796.073

796.31

http://dx.doi.org/10.1590/1807-55092015000200177

\author{
Nélio TELES* \\ Anna VOLOSSOVITCH*
}

\section{Resumo}

0 objetivo do presente estudo foi verificar a associação dos diferentes indicadores de desempenho, registados nos últimos 10 minutos do jogo de handebol, com o desfecho da partida em função da qualidade do adversário, local e equilíbrio do jogo. A amostra foi constituída por 1551 processos ofensivos e 1549 processos defensivos registados em 150 períodos de 10 minutos, observados em 75 jogos, realizados por nove equipes da Liga Portuguesa de Handebol de Seniores Masculinos na época de 2008/2009. Para o registro dos dados foi desenvolvido um sistema de observação, composto por oito variáveis de desempenho (relação numérica, fase do jogo, substituições, ações ofensivas, ações defensivas, sanções disciplinares, resultado da posse de bola e resultado do jogo) e três variáveis contextuais (local do jogo, qualidade do adversário e equilibrio da partida). A análise da relação entre o desempenho, o resultado da partida e as variáveis contextuais foi feita com recurso ao teste do Qui-quadrado e aos modelos log-lineares. Os resultados obtidos sugerem que os indicadores associados ao resultado final são: a eficácia do goleiro, a eficácia de finalização, as substituições defesa-ataque e o número de contra-ataques. 0 equilíbrio da partida relaciona-se significativamente com o número de substituições, as interrupções do ataque por faltas defensivas, a eficácia de finalização da $1^{\text {a }}$ linha e os erros ofensivos.

Palavras-chave: Análise do jogo; Último período; Variáveis situacionais; Indicadores de desempenho; Modelos log-lineares.

\section{Introdução}

A identificação das ações individuais e coletivas que contribuem de modo significativo para o sucesso competitivo constitui um dos principais problemas da análise do desempenho nos esportes coletivos. Numerosos estudos realizados na área de análise do jogo procuraram reconhecer as razóes que conduzem as equipes à vitória ou derrota, assumindo que é possível estabelecer relaçôes lineares entre as variáveis quantitativas que caracterizam o desempenho das equipes e o resultado final do encontro ${ }^{1-5}$. Reconhecendo o tempo como um dos elementos estruturais do jogo e assumindo que o rendimento das equipes varia durante a partida, torna-se evidente que o enquadramento temporal das açóes individuais e coletivas é crucial para a avaliaçáo objetiva do seu impacto no resultado final ${ }^{6}$. O contexto competitivo pode assumir vários estados em função da configuração e conjugação das variáveis do tempo e resultado e estes estados devem ser tomados em consideração na análise do desempenho das equipes ${ }^{7}$. De fato, o impacto da mesma açáo, positiva ou negativa, não é idêntico numa situação de marcador equilibrado a escassos minutos do fim da partida e num contexto de desequilíbrio ou no início do jogo.

A relação tempo-resultado foi considerada nos estudos da crise psicológica, realizados por BAR-ELI e Tenendauum $^{8-9}$ e Bar-Eli et al. ${ }^{10}$. Nestes trabalhos a qualidade do desempenho individual em diferentes períodos de jogo foi relacionada com determinados estados psicológicos, expectativas e percepçôes dos jogadores. Com base nas opiniōes dos peritos, os autores verificaram que no último período do jogo de basquetebol os praticantes em geral acusam uma maior vulnerabilidade emocional, considerado este período como o mais crítico, visto que nos últimos minutos foi registrado o maior número de infrações graves e o 
mais fraco nível de performance 9 . A mesma tendência foi registrada nos jogos de handebol e de tênis ${ }^{10}$.

Procurando esclarecer as implicaçóes psicológicas do resultado parcial do jogo, BAR-ELI e TENENBAUM ${ }^{8}$ estimaram o modelo que confirmou a influência do marcador no estado psicológico dos jogadores. A tendência negativa do resultado ou o "desenvolvimento inesperado" do jogo constituíram fatores propensos ao aumento da vulnerabilidade psicológica dos praticantes, enquanto as situaçốes de liderança prolongada não revelaram qualquer efeito significativo.

Com base no pressuposto de que no decorrer do jogo é possível identificar os intervalos temporais em que o rendimento dos jogadores tem maiores repercussôes no resultado final, os especialistas em análise do jogo procuraram comparar o desempenho das equipes em diferentes períodos da partida, no sentido de distinguir os períodos temporais em que se verificam as maiores subidas ou quebras no rendimento ${ }^{7,11-12}$.

Por exemplo, VuleTa et al. ${ }^{11}$ analisaram a influência dos gols marcados em quatro períodos de 15 minutos no resultado final dos 60 jogos do Campeonato do Mundo de Handebol de Seniores Masculinos de 2003. O segundo período de 15 minutos foi identificado como o mais produtivo para as equipes vitoriosas (quarto período no caso das equipes derrotadas), enquanto o menor número de finalizaçóes eficazes foi registrado no primeiro quarto do jogo, independentemente do resultado final. As equipes vitoriosas marcaram em média mais gols do que as derrotadas em todos os períodos de jogo analisados. Os gols marcados no segundo (do $16^{\circ}$ ao $30^{\circ}$ minuto) e no primeiro períodos (do $1^{\circ}$ ao $15^{\circ}$ minuto) revelaram-se os melhores preditores do resultado final da partida. A maior variabilidade de gols marcados no segundo período, na opiniáo de Vuleta et al. ${ }^{11}$, pode indicar uma importância acrescida do resultado alcançado neste intervalo temporal no resultado final da equipe. Por sua vez, os gols marcados no terceiro e quarto períodos de jogo estatisticamente não tiveram

\section{Método}

\section{Amostra}

A amostra foi constituída por 150 períodos de 10 minutos (os últimos minutos do jogo), registrando um total de 1551 processos ofensivos e 1549 processos defensivos, observados em 75 jogos do Campeonato da Liga Portuguesa de Handebol Masculino da época de influência na diferença pontual final. Associando os gols marcados em diferentes períodos da partida ao resultado final, VULETA et al. ${ }^{11}$ náo tomaram em consideração as características específicas do contexto competitivo relativas ao equilíbrio do resultado e nível das equipes em confronto; no entanto a literatura especializada comprova a influência significativa destas variáveis contextuais no rendimento das equipes, sugerindo a sua consideração na análise do desempenho coletivo ${ }^{13-19}$. Nesse sentido, Oliveira et al. ${ }^{12}$ analisaram o efeito do local, período do jogo e da qualidade da oposição no desempenho das equipes de handebol da Liga ASOBAL. Os resultados do estudo sugerem o maior impacto do fator casa $(71 \%)$ nos jogos entre os adversários próximos no "ranking" e menor $(55 \%)$ nos jogos em que a qualidade das equipes em confronto foi mais desequilibrada. Os autores identificaram o último período de cinco minutos de cada parte como o intervalo temporal em que as equipes marcaram o maior número de gols, principalmente na segunda parte do jogo, tendo sido registrados mais gols marcados pelas equipes visitantes.

A importância dos últimos minutos do jogo tem sido ressaltada por diversos autores, especialmente em jogos equilibrados ${ }^{20-24}$. O fato dos últimos minutos de jogo serem reconhecidos como a zona de maior risco que exige uma atitude ponderada em campo $^{24}$, justifica a pertinência da análise das açóes das equipes neste período temporal. Todavia, apesar da reconhecida relevância deste assunto na análise do desempenho nos esportes coletivos, os estudos que procuraram identificar os aspetos ofensivos e defensivos do desempenho que se associam ao sucesso das equipes nos últimos minutos do jogo de handebol ainda são muito escassos. Deste modo, o presente estudo estabeleceu como objetivo verificar a associação dos diferentes indicadores de desempenho, registrados nos últimos 10 minutos do jogo de handebol, com o desfecho da partida em função da qualidade do adversário, local e equilíbrio do jogo.

2008/2009, em que participaram nove equipes. Os jogos que terminaram com o resultado empatado foram excluídos da amostra. O processo ofensivo iniciava-se com a conquista da posse de bola e terminava quando a equipe marcava gol, realizava uma finalização sem ressalto, ou quando a equipe adversária recuperava a posse de bola. $\mathrm{O}$ ressalto ofensivo não interrompia o 
processo ofensivo. O processo defensivo correspondia à posse de bola da equipe adversária.

\section{Variáveis}

No estudo foram utilizadas dois tipos de variáveis:

1) as variáveis contextuais que caraterizam a situação competitiva em função do local do jogo, qualidade do adversário e equilíbrio da partida;

2) as variáveis de desempenho que caraterizam as açóes dos jogadores e o resultado destas açóes.

\section{Variáveis contextuais}

A variável local do jogo distingue as equipes anfitriâs das equipes visitantes.

Para quantificar o equilibrio da partida foram utilizadas duas variáveis - diferença pontual final e diferença pontual média por minuto ${ }^{6}$. Visto que no handebol em termos médios marca-se um gol por minuto ${ }^{12}$, foi utilizado o intervalo temporal de um minuto para descrever mais detalhadamente a evolução do resultado. Para classificar os jogos como equilibrados e desequilibrados foi utilizada a análise de "clusters" (método "k-means"). Foram classificados como equilibrados os jogos, cuja diferença média de gols por minuto e a diferença final situava-se entre um e cinco gols. Como desequilibrados foram classificados os jogos, cuja diferença média de gols por minuto situava-se entre oito e 13 gols e a diferença final entre um e quatro gols. O grupo de jogos equilibrados incluiu 47 jogos $(61,8 \%)$ e o grupo de jogos desequilibrados foi composto por 28 jogos (36,2\%). A distribuição dos 150 períodos de jogo observados em função das variáveis contextuais pode ser observada na TABELA 1.

A qualidade do adversário foi caraterizada em função do "ranking" das equipes na jornada anterior (foram analisados os jogos a partir da $2^{\mathrm{a}}$ rodada do Campeonato), sendo os jogos da amostra classificados em dois grupos:

1) Jogos realizados contra equipes pior classificadas (50-9o lugar no "ranking");

2) Jogos realizados contra equipes melhor classificadas (1º-4o lugar no "ranking").

TABELA 1 - Distribuição dos períodos de jogo observados em função das equipes e variáveis contextuais.

\begin{tabular}{lccccccccc}
\hline Equipe & $\begin{array}{c}\text { Total de } \\
\text { períodos } \\
\text { observados } \\
\text { por equipe }\end{array}$ & Equil. & Deseq. & Equil. & Deseq. & Equil. & Deseq. & Equil. & Deseq. \\
\hline Porto & 19 & 6 & 5 & 0 & 0 & 3 & 3 & 2 & 0 \\
Benfica & 20 & 5 & 4 & 0 & 0 & 3 & 1 & 5 & 2 \\
Sporting & 20 & 4 & 3 & 3 & 0 & 1 & 2 & 6 & 1 \\
Madeira S. & 15 & 3 & 4 & 1 & 1 & 1 & 0 & 5 & 0 \\
ABC & 16 & 3 & 1 & 3 & 0 & 4 & 1 & 4 & 0 \\
Belenenses & 14 & 3 & 2 & 2 & 0 & 1 & 0 & 3 & 3 \\
São Bernardo & 18 & 5 & 0 & 3 & 2 & 2 & 0 & 1 & 5 \\
Sp. Horta & 16 & 1 & 2 & 3 & 2 & 0 & 0 & 2 & 6 \\
Águas Santas & 12 & 0 & 1 & 2 & 2 & 1 & 0 & 3 & 3 \\
Total & 150 & 30 & 22 & 17 & 7 & 16 & 7 & 31 & 20 \\
\hline
\end{tabular}

\section{Variáveis de desempenho}

Para alcançar os objetivos do estudo foi desenvolvido um sistema de observaçáo que permitiu registrar e analisar as açôes ofensivas e defensivas das equipes nos últimos 10 minutos da partida. A seleção das variáveis para a análise das açôes dos jogadores durante os processos ofensivos e defensivos foi feita com base nos estudos realizados na área de análise do jogo de handebol ${ }^{2,25-28}$.
Na TABELA 2 estão apresentadas as variáveis e as respectivas classes que foram incluídas no sistema de observação elaborado para o estudo.

O sistema de observação foi validado por três peritos na área do handebol - dois docentes do Ensino Superior (um Doutorado e outro a realizar Doutoramento em Ciências do Desporto na área de análise do jogo de handebol) e um treinador de handebol de nível IV (certificado de Master Coach da EHF). 
TABELA 2 - Variáveis utilizadas no sistema de observação.

\begin{tabular}{|c|c|}
\hline Variáveis de desempenho & Classes \\
\hline Relação numérica & Igualdade numérica; Superioridade numérica; Inferioridade numérica. \\
\hline Fase do jogo & $\begin{array}{l}\text { Recuperação defensiva; Defesa organizada; Contra-ataque (direto e apoiado); } \\
\text { Ataque organizado. }\end{array}$ \\
\hline Substituições & $\begin{array}{l}\text { Ataque-defesa /Defesa-ataque. } \\
\text { Sem substituiçóes; Uma substituição; Duas substituiçôes; Mais do que duas substituiçôes }\end{array}$ \\
\hline Açốes ofensivas & 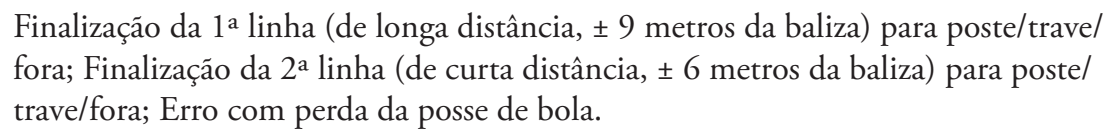 \\
\hline Açôes defensivas & $\begin{array}{l}\text { Interceção/Desarme; Bloco sem ficar com a posse de bola ; Bloco com ganho da } \\
\text { posse de bola (interceção da bola durante a finalização por um ou dois defesas); } \\
\text { Defesa do goleiro sem ficar com a posse de bola; Defesa do goleiro com ganho da } \\
\text { posse de bola; Falta defensiva; Falta defensiva que origina } 7 \mathrm{~m} \text {. }\end{array}$ \\
\hline Sançôes disciplinares & $\begin{array}{l}\text { Advertência ao ataque; Advertência à defesa; Exclusão de } 2 \text { minutos ao atacante; } \\
\text { Exclusão de } 2 \text { minutos ao defensor. }\end{array}$ \\
\hline Resultado & $\begin{array}{l}\text { Gol; Defesa do goleiro; Bloco; Finalização fora/trave/poste; Interceçấ/ Desarme; } \\
\text { Falha técnica com perda da posse de bola. }\end{array}$ \\
\hline
\end{tabular}

\section{Coleta de dados}

Os vídeos dos jogos foram cedidos pela Liga Portuguesa de Andebol em CD-RW. Através do programa DVD Shrink foram selecionados e gravados os últimos 10 minutos de cada partida para a sua posterior análise. Para a recolha dos dados foi utilizado o "software" Match Vision Studio ${ }^{29}$, que permitiu o registro das açóes ofensivas e defensivas incluídas no sistema de observação.

\section{Reprodutibilidade dos dados}

Para testar a fiabilidade intra-observador foi cumprido um protocolo de observaçáo. O protocolo decorreu em dois momentos distintos, separados por 15 dias, e consistiu na observação e anotação dos dados referentes a $10 \%$ do total da amostra. Os resultados das duas observaçóes foram comparados. Para o cálculo da fiabilidade foi utilizada a fórmula de BELLACK et al. ${ }^{30}$. Nos resultados obtidos a percentagem de acordos variou entre $95 \%$ e $100 \%$, comprovando bons índices de fiabilidade, que segundo a recomendaçáo de BELLACK et al. ${ }^{30}$ devem situar-se acima dos $80-85 \%$.

\section{Procedimentos estatísticos}

Para evitar a elevada dispersão dos dados e reduzido número de observaçôes, referentes a determinadas classes das variáveis, estas foram reclassificadas segundo a regra de $S_{\text {TURGes }}{ }^{31}$. A regra indica que o número de classes $\kappa$ é dado pela seguinte equação: $\kappa=\left[1+\log _{2} \eta\right]$, onde $\kappa$ é o número de classes e $\eta$ é a amplitude amostral.

Após o registro e a análise de frequência de ocorrências das variáveis de desempenho e a sua reclassificação de acordo com a regra de Sturges, foram estimados os modelos Log-lineares Hierárquicos do tipo "Backward". A vantagem da utilização da análise Log-linear reside no fato desta permitir identificar e hierarquizar todas as interações significativas entre mais que duas variáveis categóricas, sem as distinguir como dependentes e independentes ${ }^{32-33}$. No presente estudo a modelação Log-linear foi utilizada para testar os efeitos de interação de $1^{\mathrm{a}}, 2^{\mathrm{a}}$ e $3^{\mathrm{a}}$ ordem entre as variáveis de desempenho, o resultado final do jogo e as variáveis contextuais ${ }^{32-35}$. Primeiro as variáveis foram organizadas em tabelas de contingência multidimensionais e os dados foram analisados no sentido de garantir que o tamanho da amostra e as frequências esperadas estavam de acordo com pressupostos da modelação. A análise Log-linear Hierárquica foi realizada a partir do modelo saturado com recurso à estratégia "Backward" que visa estimar o modelo mais parcimonioso eliminando as interações mais complexas não significativas. $\mathrm{O}$ nível de significância dos modelos Log-lineares e a qualidade do ajustamento foram avaliados com estatísticas $\mathrm{G}^{2}$ e $\mathrm{x}^{2}$.

O teste do Qui-quadrado foi utilizado para analisar a relação entre as variáveis contextuais e o resultado 
final do jogo, tal como para avaliar e interpretar as associações entre diferentes classes das variáveis de desempenho e contextuais que se mostraram interrelacionadas na sequência da modelação Log-linear ${ }^{33}$.
O nível de significância estabelecido para todos os testes foi de $p \leq 0,05$. No tratamento estatístico dos dados foi utilizado o "software" SPSS (Statistical Package for Social Science) for Windows ${ }^{\oplus}$, versão 20.0.

\section{Resultados}

\section{Análise da relação entre o resultado final do jogo e as variáveis contextuais}

A relação entre as variáveis contextuais e o resultado final do jogo foi analisada através do teste do Qui-quadrado, cujos resultados estão apresentados na TABELA 3. Este procedimento permitiu identificar uma relaçáo significativa $(p<0,001)$ entre o resultado final do jogo, o local da partida e a qualidade do adversário. A análise dos resíduos ajustados estandardizados confirma uma associaçáo positiva entre o número de vitórias e o número de jogos realizados em casa e negativos entre o número de vitórias e o número de jogos realizados fora. Em $66,7 \%$ dos jogos as equipes visitantes perderam. A análise da relação entre a qualidade do adversário e o resultado final do jogo permitiu constatar que, como seria de esperar, jogando contra adversários mais fracos, as equipes venceram $64,2 \%$ dos encontros e apenas 33\% jogando contra adversários mais fortes. De acordo com os resíduos ajustados estandardizados, uma associação significativa positiva foi registada entre o número de derrotas e a classe adversário forte e entre o número de vitórias e a classe adversário fraco (TABELA 3).

TABELA 3 - Resultado do teste do Qui-quadrado para o desfecho do jogo analisado em função das variáveis contextuais.

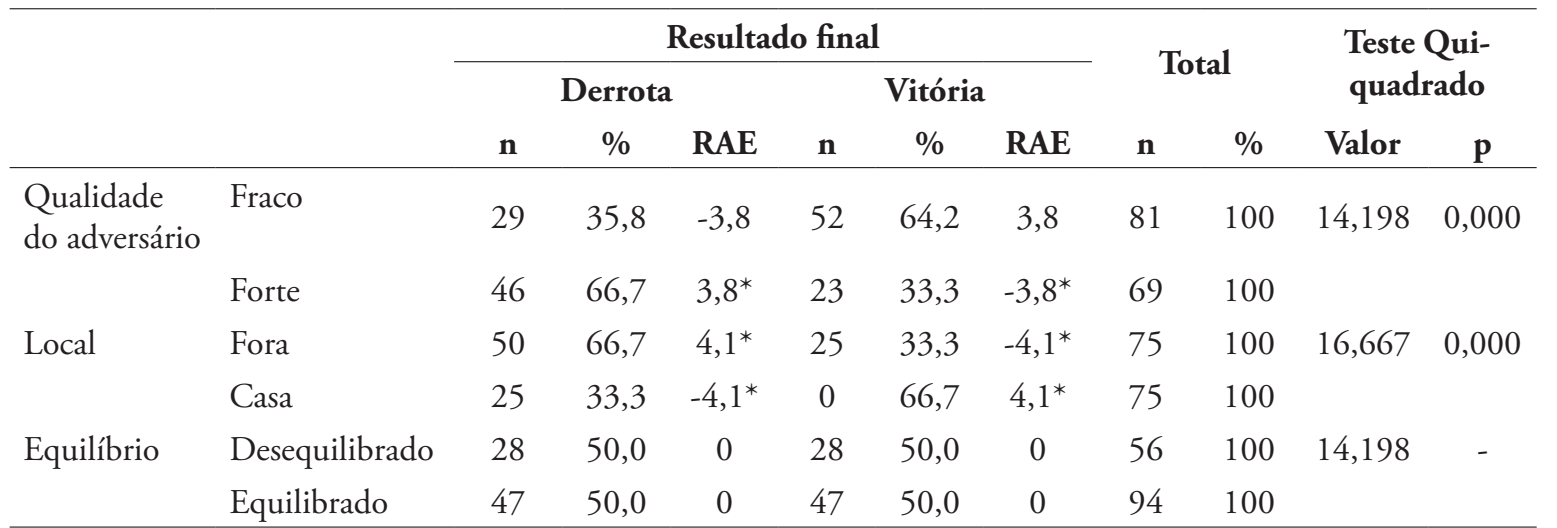

${ }^{*}$ Resíduos ajustados estandardizados (RAE) significativos $(\geq \pm 1,96)$.
Visto que cada equipe realizou um número de jogos diferente, na análise interativa entre as variáveis contextuais foram utilizadas as frequências relativas. Os dados indicam que em $72,2 \%$ dos jogos disputados em casa foi registrado um contexto de desequilíbrio com a vitória das equipes melhor classificadas. Em $76 \%$ dos jogos disputados em casa as equipes pior classificadas perderam num contexto de equilíbrio (com diferença pontual inferior a cinco gols).

Por sua vez, a derrota das equipes anfitriâs melhor classificadas aconteceu na maioria dos casos em contexto de equilíbrio (23,5\% dos jogos equilibrados e $14,3 \%$ dos jogos desequilibrados).

Nos jogos equilibrados realizados fora de casa as melhores e piores equipes obtiveram a mesma percentagem de vitórias (50\%). Os resultados dos jogos desequilibrados, realizados fora de casa, são mais previsíveis - $85,7 \%$ de vitórias para as equipes melhor classificadas e $14 \%$ para as equipes pior classificadas.

\section{Análise das interações entre as variáveis contextuais, o resultado final do jogo e as variáveis de desempenho registradas nos últimos 10 minutos da partida}

Numa segunda fase do estudo através da modelação Log-linear Hierárquica foram analisadas as interaçóes de $1^{\mathrm{a}}, 2^{\mathrm{a}}$ e $3^{\mathrm{a}}$ ordem entre as variáveis de desempenho registradas nos últimos 10 minutos da partida, o resultado do jogo e as variáveis contextuais. 
Com vista a encontrar os modelos mais parcimoniosos e adequados para explicar as frequências das ações observadas, foram estimados 40 modelos log-lineares hierárquicos. Os modelos finais que mostraram um bom ajustamento aos dados evidenciaram a existência de interaçóes apenas da $2^{\text {a }}$ ordem, conforme apresentado na TABELA 4.

TABELA 4 - Relações entre as variáveis de desempenho, o resultado do jogo e as variáveis contextuais identificadas através da modelação Log-linear Hierárquica.

\begin{tabular}{|c|c|c|c|}
\hline Efeito & df & Qui-quadrado parcial & $\mathbf{p}$ \\
\hline Resultado final * Defesas do goleiro & 5 & 21,745 & 0,001 \\
\hline Resultado final * Eficácia de finalização da $1^{\text {a }}$ linha & 3 & 12,235 & 0,007 \\
\hline Resultado final * Eficácia de finalização da 2a linha & 3 & 10,972 & 0,012 \\
\hline Resultado final $*$ Substituiçóes defesa-ataque & 5 & 16,070 & 0,007 \\
\hline Resultado final ${ }^{*}$ Total de contra-ataques & 6 & 13,423 & 0,037 \\
\hline Equilíbrio $*$ Substituiçóes ataque-defesa & 5 & 14,201 & 0,014 \\
\hline Equilíbrio * Substituiçóes defesa-ataque & 5 & 14,865 & 0,011 \\
\hline Equilíbrio * Interrupçóes & 4 & 11,041 & 0,026 \\
\hline Equilíbrio * Erros & 3 & 8,008 & 0,046 \\
\hline Equilíbrio * Eficácia de finalização da $1^{\text {a }}$ linha & 3 & 8,705 & 0,033 \\
\hline Equilíbrio & 1 & 9,732 & 0,002 \\
\hline Defesas do goleiro & 5 & 226,997 & 0,000 \\
\hline Substituições Ataque-defesa & 5 & 36,384 & 0,000 \\
\hline Interrupçóes & 4 & 43,918 & 0,000 \\
\hline Eficácia da $1^{\text {a }}$ linha & 3 & 26,737 & 0,000 \\
\hline Eficácia da 2a linha & 3 & 76,030 & 0,000 \\
\hline Erros & 3 & 173,983 & 0,000 \\
\hline Substituiçóes defesa-ataque & 5 & 30,130 & 0,000 \\
\hline Total de contra-ataques & 6 & 134,932 & 0,000 \\
\hline No de posses de bola & 4 & 108,377 & 0,000 \\
\hline
\end{tabular}

A análise da interação entre o resultado final e defesas do goleiro demonstrou que o goleiro da equipe que está a perder nos últimos 10 minutos efetua entre zero e uma defesas em mais de $50 \%$ dos jogos. No entanto, quando a equipe observada está a ganhar, o número de defesas do goleiro é igual ou superior a três, representando uma eficácia de 50\% nos últimos 10 minutos de jogo.

Para melhor entender as associaçóes entre as classes das variáveis resultado final e defesas do goleiro foi utilizado o teste do Qui-quadrado e calculados os resíduos ajustados estandardizados (RAE), como sugerido por FIELD $^{33}$. Os resultados desta análise confirmaram uma associação significativa positiva entre a classe derrota e uma defesa do goleiro $\left(\chi^{2}=20,715, \mathrm{p}<0,01\right.$, RAE $=3,4)$, tal como uma associação positiva entre quatro defesas do goleiro e classe vitória (RAE $=3,0)$.

De acordo com os resultados do teste do Quiquadrado, a eficácia de finalização entre 25 e 50\% está positivamente associada com a classe derrota $\left(\chi^{2}\right.$
$=11,623, \mathrm{p}<0,01, \mathrm{RAE}=2,7)$, enquanto a eficácia entre 50 e 75\% com a classe vitória $(\mathrm{RAE}=2,5)$.

Uma tendência semelhante foi observada na relação entre o resultado final do jogo e a eficácia de finalização da $2^{\text {a }}$ linha. As equipes cuja eficácia de finalização da

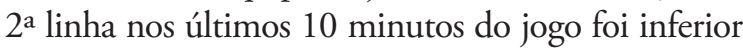
a $25 \%$ ficaram relacionadas significativamente com a classe derrota $\left(\chi^{2}=10,174, \mathrm{p}<0,05, \mathrm{RAE}=2,4\right)$, enquanto as equipes que mostraram uma eficácia superior a $75 \%$ ganharam em $58,7 \%$ dos casos, estando associados significativamente à classe vitória (RAE = $2,5)$. Estes resultados permitem afirmar que as equipes que não alcançam uma eficácia de $50 \%$ na finalização da $1^{\text {a }}$ linha e uma eficácia de $75 \%$ na finalização da $2^{\text {a }}$ linha nos últimos 10 minutos de jogo reduzem consideravelmente a sua probabilidade de ganhar a partida.

Os resultados do teste do Qui-quadrado confirmaram que o número de substituiçóes defesa-ataque nos últimos 10 minutos do jogo está relacionado 
com o desfecho da partida. A associação positiva significativa foi registrada entre a derrota e classes de zero substituiçóes e uma substituição $\left(\chi^{2}=30,470\right.$, $\mathrm{p}<0,05, \mathrm{RAE}=2,2$ e RAE 2,9, respetivamente), enquanto o resultado vitória foi positivamente associado à classe de oito substituiçôes $(\mathrm{RAE}=2,4)$.

$\mathrm{O}$ número total de contra-ataques organizados nos últimos 10 minutos do jogo também revelou uma relação significativa com o resultado final. As equipes derrotadas organizaram maior número de contra-ataques, comparativamente com as equipes vitoriosas, mais concretamente, a classe de três contra-ataques associa-se positivamente com a derrota e negativamente com a vitória $\left(\chi^{2}=10,208, \mathrm{p}\right.$ $<0,05, \mathrm{RAE}=2,4$ e RAE -2,4, respectivamente).

A análise das relaçóes entre a variável equilíbrio e os indicadores de desempenho permitiu identificar uma associação positiva significativa entre o resultado desequilibrado e o número de substituiçôes ataque-defesa inferior a $2\left(\chi^{2}=13,365, \mathrm{p}<0,05\right.$, $\mathrm{RAE}=2,4)$, tal como uma associação positiva entre 3-5 substituiçóes defesa-ataque e o contexto de desequilíbrio $\left(\chi^{2}=14,281, \mathrm{p} \leq 0,05, \mathrm{RAE}=2,3\right.$.

A comparação dos dois contextos de equilíbrio permite constatar que em jogos equilibrados ocorrem mais substituiçóes, atingindo um total de $68,5 \%$ entre as seis e 20 substituiçóes.

\section{Discussão}

Os resultados do presente estudo confirmaram o efeito significativo das variáveis contextuais no resultado final do jogo no handebol português de alto rendimento. Tanto o local do jogo, como a qualidade do adversário revelaram-se relacionados com o desfecho da partida.

A influência do local do jogo no rendimento das equipes tem sido amplamente estudada nos jogos desportivos coletivos ${ }^{13-14,35-37}$. Os nossos dados comprovam a vantagem de jogar em casa no handebol português e neste sentido são semelhantes aos resultados recentemente registados na Liga Espanhola ASOBAL $^{12,19}$. Foi verificado que, jogando em casa, as equipes da Liga Portuguesa ganharam 66,7\% dos encontros. Este valor é superior aos registrados na Liga Espanhola (60,4\% e 64\%) por Pollard e GómEz ${ }^{21}$ e por Oliveira et al. ${ }^{12}$. Esta diferença pode ser explicada não apenas pela diferença do nível competitivo das Ligas, mas também pela forma de cálculo da vantagem casa. No nosso estudo e no estudo de Oliveira
A análise das interrupçóes efetuadas pelos jogadores defesas demonstrou que nos últimos 10 minutos dos jogos equilibrados a percentagem de ocorrência entre quatro e seis interrupçóes é superior à ocorrência de mais de seis interrupçóes. As associaçôes positivas foram registradas entre a classe de 7-9 interrupçóes efetuadas pelos defesas e o resultado desequilibrado $\left(\chi^{2}=10,535, \mathrm{p}<0,05, \operatorname{RAE}=2,2\right)$, tal como entre a classe de 10-12 interrupçóes e o resultado equilibrado $(\mathrm{RAE}=2,1)$.

Nos jogos equilibrados foi registrada uma menor percentagem de erros ofensivos, comparativamente com os jogos desequilibrados. A percentagem de erros inferior a $25 \%$ foi associada positivamente com o contexto de equilíbrio $\left(\chi^{2}=7,994, \mathrm{p}<0,05\right.$, $\mathrm{RAE}=2,8)$, enquanto a percentagem de erros entre 25 e $50 \%$ foi positivamente associada ao resultado desequilibrado do jogo ( $\mathrm{RAE}=2,6)$.

Relaçôes significativas foram observadas entre o equilíbrio da partida e a eficácia de finalização da

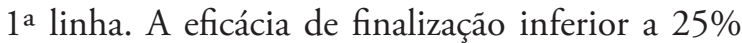
revelou uma associaçáo significativa com o contexto de desequilíbrio $\left(\chi^{2}=7,994, \mathrm{p}<0,05, \mathrm{RAE}=2,8\right)$.

As variáveis contextuais local do jogo e qualidade do adversário não demonstraram qualquer efeito significativo nas variáveis de desempenho registadas nos últimos 10 minutos de jogo.

et al. ${ }^{12}$ foi calculada a percentagem de vitórias e no estudo de Pollard e Gómez ${ }^{21}$ foi utilizada a percentagem de pontos ganhos em casa (os pontos dos jogos que terminaram com empate também foram considerados). Os resultados do nosso estudo indicam que as equipes anfitriâs melhor classificadas ganharam a maioria dos jogos $(72,7 \%)$ com um resultado desequilibrado, enquanto as equipes anfitriãs pior classificadas venceram $60 \%$ dos jogos num contexto de equilíbrio. Oliveira et al. ${ }^{12}$ identificaram que na Liga ASOBAL a vantagem de jogar em casa foi superior nos jogos equilibrados $(71 \%)$, comparativamente com os desequilibrados $(55 \%)$, mas neste caso a qualidade das equipes não foi considerada.

O local do jogo não evidenciou qualquer efeito significativo nas variáveis de desempenho registradas nos últimos 10 minutos da partida. Eventualmente, a influência dos fatores associados à vantagem casa, como o apoio do público e a familiaridade com as instalaçóes, deve ser analisada ao nível macro, com 
recurso às variáveis que avaliam globalmente o rendimento das equipes, ao contrário dos indicadores de desempenho utilizados no nosso estudo, que registraram os aspectos particulares do desempenho e apenas durante os últimos 10 minutos do jogo. A mesma análise pode ser feita em relação à variável qualidade do adversário, que também não revelou efeito significativo nas variáveis de desempenho registradas nos últimos minutos do jogo.

As associações encontradas no nosso estudo entre a eficácia do goleiro e o resultado final da partida não são surpreendentes e estão em conformidade com os resultados dos trabalhos que analisaram a influência deste posto específico no rendimento das equipes de handebol ${ }^{2,26}$. A eficácia do goleiro em parte expressa a qualidade da defesa da equipe em geral - que é particularmente importante nos últimos minutos de jogo. Como foi demonstrado no estudo de Volossovitch ${ }^{6}$ e Dumangane et al. ${ }^{38}$, a probabilidade de marcar gol e, consequentemente, vencer o jogo em grande medida depende da eficácia defensiva das equipes, principalmente nas últimas cinco posses de bola.

Como seria de esperar, a eficácia de finalização da $1^{a}$ $e 2^{a}$ linhas revelou uma forte associação com o resultado final do jogo. As açóes de finalização, juntamente com a eficácia do goleiro, são indicadores de desempenho com influência indiscutível no rendimento das equipes, o que foi confirmado por vários estudos realizados na área de análise do jogo ${ }^{2,12,25-26,39-40}$. No entanto, alguns dos estudos sugerem um maior impacto de finalização da $1^{\text {a }}$ linha no resultado final do jogo $^{2}$, enquanto outros realçam a importância da eficácia de finalização dos jogadores pontas ${ }^{40}$. O nosso estudo revela que a eficácia de finalização da $1^{a}$ linha ganha uma importância significativamente maior no contexto dos jogos equilibrados.

Uma relação interessante foi encontrada entre o número de substituiçóes realizadas nos últimos $10 \mathrm{mi}-$ nutos do jogo em diferentes contextos competitivos. A utilização das substituiçôes no jogo de handebol é um assunto muito pouco estudado, sendo mencionado na literatura apenas em associação com as lesóes. Os nossos resultados indicam que os treinadores das equipes derrotadas utilizaram muito poucas substituiçóes defesa-ataque ou um número bastante elevado destas. Segundo os resultados, nenhuma destas duas soluções táticas revelou-se profícua, tendo em consideração que o número de substituiçôes defesa-ataque utilizadas pelas equipes vitoriosas nos últimos 10 minutos de jogo situou-se predominantemente entre seis e oito.

No contexto de equilíbrio em $33 \%$ dos jogos foram utilizadas entre seis e oito substituiçôes nos últimos 10 minutos, sendo este número de substituiçôes mais utilizado pelos treinadores portugueses em geral. Um resultado muito semelhante foi observado para as substituiçóes defesa-ataque nos jogos equilibrados, em que os treinadores procuraram aproveitar ao máximo os seus melhores atacantes nas açôes ofensivas.

Como os resultados demonstram, nos últimos 10 minutos de jogo em $60,7 \%$ dos jogos vitoriosos as equipes realizaram entre um e dois contra-ataques. Mais que três contra-ataques foram organizados predominantemente pelas equipes derrotadas. Este resultado pode indicar que face à diferença pontual desfavorável, as equipes arriscam mais, utilizando o contra-ataque com o objetivo de inverter o resultado.

A análise de erros ofensivos cometidos durante os últimos 10 minutos demostrou que a sua menor percentagem (inferior a 25\%) foi registrada nos jogos equilibrados, revelando que neste contexto as equipes procuram controlar melhor as suas açóes face à importância destas para o resultado final.

$\mathrm{O}$ número de interrupçóes efetuadas pelos jogadores defesas manifestou uma relação significativa com a variável equilíbrio do jogo, no entanto a diferença entre as interrupçóes efetuadas nos jogos equilibrados e desequilibrados não foi muito grande. Os resultados parecem indicar que nos jogos equilibrados a circulação de bola adversária é interrompida mais frequentemente do que nos jogos desequilibrados. Isto poderá expressar o maior empenho defensivo nos contextos equilibrados e a intenção dos defesas de quebrar o ritmo de ataque adversário através de faltas para evitar a finalização.

Um dos principais contributos do presente estudo para o conhecimento sobre o jogo de handebol passa pela avaliação do efeito dos fatores contextuais no desempenho das equipes nos últimos minutos da partida. O desempenho coletivo neste caso foi caracterizado por alguns indicadores ainda pouco utilizados na análise notacional em handebol, como o número e tipo de substituiçóes e o número de interrupções do processo ofensivo dos adversários.

Os resultados do estudo indicam que o desfecho da partida é influenciado pelo local do jogo e pela qualidade do adversário. O comportamento das equipes e as opçóes dos treinadores quanto às substituiçôes nos últimos 10 minutos depende do equilíbrio da partida, que tem um impacto significativo sobre a maioria dos indicadores analisados. O conhecimento das tendências de comportamento das equipes em situaçóes de maior (ou menor) equilíbrio pode ajudar o treinador a antecipar as açóes do adversário, tomando as decisóes 
estratégicas e táticas mais adequadas. A eficácia de finalização e do goleiro, o número de contra-ataques e as substituiçóes defesa-ataque, realizadas nos últimos 10 minutos do jogo, foram identificados como os indicadores que se associam significativamente com o resultado final da partida.

Em termos práticos os resultados do presente estudo sugerem que os treinadores devem preparar diferentes soluçôes tácticas para diferentes contextos competitivos com o intuito de facilitar a atuação das equipes nos últimos 10 minutos do jogo, principalmente em contexto de equilíbrio, quando o resultado da partida pode ser decidido por uma ação. Uma atenção particular deve ser atribuída ao treino específico do goleiro, articulando o mesmo com o trabalho defensivo no sentido de estimular uma atitude proactiva dos defesas. O aperfeiçoamento da finalização, principalmente da $1^{a}$ linha, deve ser uma das preocupaçóes constantes que permitirá aumentar a quantidade e qualidade das soluções ofensivas das equipes.

\begin{abstract}
The influence of contextual variables on the team's performance in the last 10 minutes of the handball match

The purpose of this study was to verify the association of different performance indicators, registered in the last ten minutes of handball game, with the match outcome according to quality of opposition, game location, and match equilibrium. The sample consisted of 1551 offensive processes and 1549 defensive processes recorded in 150 ten-minute periods from 75 matches played by nine teams from the Portuguese Handball Men League in the 2008/2009 season. The observational system included eight performance variables (numerical relationship, game phase, substitutions, offensive actions, defensive actions, personal punishments, result of ball possession and match outcome) and three contextual variables (game location, quality of opposition and match equilibrium). The relationship between performance and contextual variables has been analyzed using log-linear models and chi-square test. The results suggest that the indicators associated with the match outcome are: the goalkeeper efficacy, the shot efficacy, the defense-attack substitutions and total of fast breaks. The match equilibrium was significantly related to the number of substitutions, defensive fouls, offensive errors and the efficacy of long-distance throws.
\end{abstract}

KEY WoRDS: Match analysis; Last game period; Situational variables; Performance indicators; Log-linear models.

\title{
Referências
}

1. Sampaio J, Janeira M. Statistical analyses of basketball team performance: understanding teams' wins and losses according to a different index of ball possessions. Int J Perform Anal Sport. 2003;3:40-9.

2. Volossovitch A, Ferreira AP, Gonçalves I. The use of binominal logistic regression in performance analysis in handball. Int J Comp Sci Sport. 2003;2:145.

3. Jones N, Mellalieu SD, James N. Team performance indicators as a function of winning and losing in rugby union. Int J Perform Anal Sport. 2004;4:61-71.

4. Csataljay G, O’Donoghue P, Hughes M, Dancs H. Performance indicators that distinguish winning and losing teams in basketball. Int J Perform Anal Sport. 2009;9:60-6.

5. Vaz L, Mouchet A, Carreras D, Morente H. The importance of rugby game-related statistics to discriminate winners and losers at the elite level competitions in close and balanced games. Int J Perform Anal Sport. 2011;11:130-41.

6. Volossovitch, A, Dumangane, M, Rosati, N. Factores que influenciam a dinâmica do rendimento colectivo no andebol. Rev Española Educ Fís Deportes. 2012;396:13-33.

7. Martín R, Lago C. Deportes de equipo Comprender la complejidad para elevar el rendimiento. Barcelona: INDE; 2005.

8. Bar-Eli M, Tenenbaum G. Game standings and psychological crisis in sport: theory and research. J Sports Sci. 1989;14:31-7. 
9. Bar-Eli M, Tenenbaum G. Observation of behavioral violations as crisis indicators in competition. Sport Psychol. 1989;3:237-44.

10. Bar-Eli M, Taoz E, Levy-Kolker N, Tenenbaum G. Performance quality and behavioral violations as crisis indicators in competition. Int J Sport Psychol. 1992;3:325-42.

11. Vuleta D, Milanovic D, Grunic I, Ohnjec K. Influence of the goals scored in the different time periods of the game on the final outcome of matches of the 2003 Men's World Handball Championships, Portugal. EHF Periodical [Internet]. 2007. Available from: http://home.eurohandball.com/ehf_files/Publikation/WP Vuleta-Influence of the gaols scored on final outcomes.pdf.

12. Oliveira T, Gómez M, Sampaio J. Effects of game location, period, and quality of opposition in elite handball performances. Percept Motor Skill. 2012;114:783-94

13. Carron A, Loughhead T, Bray S. The home advantage in sport competitions: Courneya and Carron's (1992) conceptual framework a decade later. J Sports Sci. 2005;23:395-407.

14. Pollard R. Home advantage in soccer: variations in its magnitude and a literature review of the inter-related factors associated with its existence. J Sport Behav. 2006;29:169-89.

15. Downward P, Jones M. Effects of crowd size on referee decisions: analysis of the FA Cup. J Sports Sci. 2007;25:1541- 5.

16. Taylor J, Mellalieu S, James N, Shearer D. The influence of match location, quality of opposition, and match status on technical performance in professional association football. J Sports Sci. 2008;26:885-95.

17. Marcelino R, Mesquita I, Palao JM, Sampaio J. Home advantage in high-level volleyball varies according to set number. J Sports Sci Med. 2009;8:352-6.

18. Lago C. The influence of match location, quality of opposition, and match status on possession strategies in professional association football. J Sports Sci. 2009;27:1463-9.

19. Pollard R, Gómez M. Re-assessment of home advantage in Spanish Handball: comment on Gutiérrez, et al. (2012). Percep Motor Skills. 2012;115:937-43.

20. Kozar B, Vaught R, K. W, Lord R, Dye B. Importance of free-throws at various stages of basketball game. Percept Motor Skill. 1994;78:243-8.

21. Navarro R, Lorenzo A, Gómez MA, Sampaio J. Analysis of critical moments in the League ACB 2007-08. Rev Psicol Deporte. 2009; 18(Suppl):391-5.

22. Gómez MA, Lorenzo A, Ibañez SJ, Sampaio J. Ball possession effectiveness in men's and women's elite basketball according to situational variables in different game periods. J Sports Sci. 2013;31:1578-87.

23. Ferreira AP. From game momentum to criticality of game situations. In: McGarry T, O’Donoghue P, Sampaio J, editors. Handbook of sports performance analysis. London: Routledge; 2013. p.270-82.

24. Gomes F, Volossovitch A, Ferreira AP. Team timeout calling in handball. Int J Perform Anal Sport. 2014;14:98-110.

25. Lago C, Gómez MA, Viaño J, González I, Fernández MA. Home advantage in elite handball: the impact of the quality of opposition on team performance. Int J Perform Anal Sport. 2013;13:724-33.

26. Prudente J. Análise da performance táctico-técnica no handebol de alto nível [tese]. Funchal: Universidade da Madeira; 2006.

27. Bilge M. Game Analysis of Olympic, World and European Championships in Men's Handball. J Hum Kinet. 2012;35:109-18.

28. Silva JA. Modelação táctica do processo ofensivo no handebol: estudo das situaçôes de igualdade numérica, 7 vs 7 , com recurso à análise sequencial [tese]. Porto: Universidade do Porto, FCDEF; 2008.

29. Perea AE, Alday L, Castellano J. Registro de datos observacionales a partir del MATCH VISION STUDIO v1.0. In: Castellano J, Sautu LM, Villaseñor AB, Mendo AH, Gońi A, Martínez F, editors. socialización y deporte: revisión crítica. Vitoria-Gasteiz: Arabako Foru Aldundia-Diputación Foral de Álava; 2006. p.135-52.

30. Bellack A, Kliebard H, Hyman R, Smith F. The language of classroom teaches college. New York: Columbia University Press; 1996.

31. Pestana, M, Gageiro, J. Análise de dados para ciências sociais: a complementaridade do SPSS. 4a ed. Lisboa: Ediçôes Sílabo; 2005.

32. Marôco J. Análise estatística com o PASW statistics. Perô Pinheiro: Report Number; 2010.

33. Field A. Discovering statistics using SPSS. London: Sage; 2009.

34. Nevill AM, Atkinson G, Hughes MD, Cooper S. Statistical methods for analysing discrete and categorical data recorded in performance analysis. J Sports Sci. 2002;20:829-44.

35. Taylor J, Mellalieu S, James N, Sheraer D. The influence of match location, quality of opposition and match status on technical performance in professional association football. J Sports Sci 2008;26:885-95. 
36. Madrigal R, James J. Team quality and the home advantage. J Sport Behav. 1999;22:381-98.

37. Pollard R. Home advantage in football: a current review of an unsolved puzzle. Open Sports Sci J. 2008;1:12-4.

38. Dumangane M, Rosati N, Volossovitch A. Departure from independence and stationarity in a handball match. J Appl Stat. 2009;36:723-41.

39. Gruic I, Vuleta D, Milanovic D. Performance indicators of teams at the 2003 Men's World Handball Championship in Portugal. Kinesiology. 2006;38:164-75.

40. Ohnjec K, Vuleta D, Milanovic D, Gruic I. Performance indicators of teams at the 2003 World Handball Championship for women in Croatia. Kinesiology. 2008;40:69-79.

\begin{tabular}{r|l} 
ENDEREÇO & \\
Anna Volossovitch & \\
Motricidade Humana & Recebido para publicação: 29/06/2014 \\
da Costa, 1495-688 & 1a. Revisão: 23/10/2014 \\
isboa - PORTUGAL & 2a. Revisão: 19/01/2015 \\
Aceito: 19/01/2015
\end{tabular}

Rev Bras Educ Fís Esporte, (São Paulo) 2015 Abr-Jun; 29(2):177-87 • 187 